
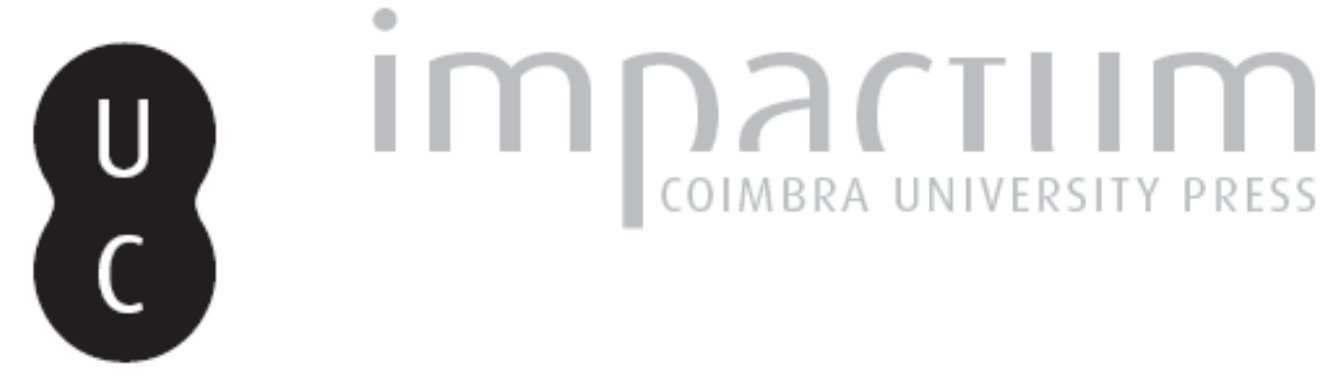

\title{
[Recensão a] Fisher-Hansen, Tobias; Poulsen, Birte - From artemis to Diana: the goddess of man and beast
}

Autor(es): $\quad$ Santos, Nídia

Publicado por: Centro de História da Universidade de Lisboa

URL persistente:

URI:http://hdl.handle.net/10316.2/23708

DOI:

DOI:http://dx.doi.org/10.14195/0871-9527_21_27

Accessed : $\quad$ 26-Apr-2023 15:02:29

A navegação consulta e descarregamento dos títulos inseridos nas Bibliotecas Digitais UC Digitalis, UC Pombalina e UC Impactum, pressupõem a aceitação plena e sem reservas dos Termos e Condições de Uso destas Bibliotecas Digitais, disponíveis em https://digitalis.uc.pt/pt-pt/termos.

Conforme exposto nos referidos Termos e Condições de Uso, o descarregamento de títulos de acesso restrito requer uma licença válida de autorização devendo o utilizador aceder ao(s) documento(s) a partir de um endereço de IP da instituição detentora da supramencionada licença.

Ao utilizador é apenas permitido o descarregamento para uso pessoal, pelo que o emprego do(s) título(s) descarregado(s) para outro fim, designadamente comercial, carece de autorização do respetivo autor ou editor da obra.

Na medida em que todas as obras da UC Digitalis se encontram protegidas pelo Código do Direito de Autor e Direitos Conexos e demais legislação aplicável, toda a cópia, parcial ou total, deste documento, nos casos em que é legalmente admitida, deverá conter ou fazer-se acompanhar por este aviso.

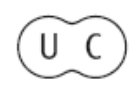



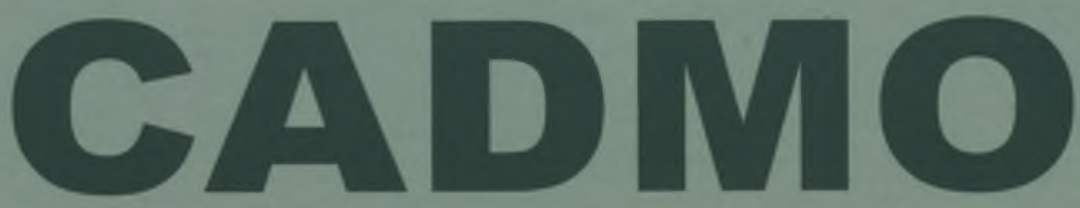

Revista de História Antiga

\author{
Centro de História \\ da Universidade de Lisboa
}

\title{
21
}

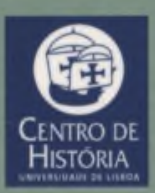

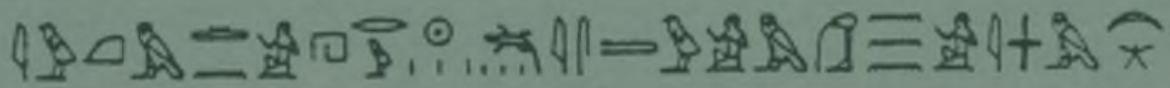

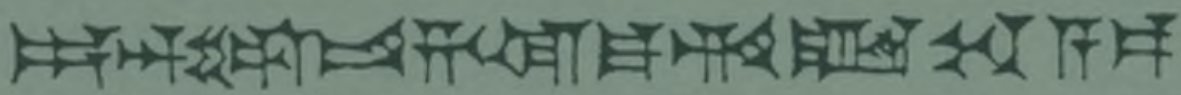

MHNIN AEI $\Delta \mathrm{E} \Theta \mathrm{EA}$ ПH$\Lambda \mathrm{HIA} \triangle \mathrm{E} \Omega$ 
TOBIAS FISHER-HANSEN, BIRTE POULSEN (ed.), From Artemis to Diana: the goddess of man and beast, Acta Hyperborea, Copenhaga: Museum Tusculanum Press, University of Copenhagen, 2009, pp. 585, ISBN: 9788763507882

Este volume das Actas Hyperborea afigura-se uma preciosa contribuição para o estudo de Ártemis/Diana na Antiguidade. Reúne as comunicações apresentadas numa conferência que decorreu na Universidade de Copenhaga em Março de 2005, a que se juntaram ainda outras colaborações inéditas que enriquecem a obra. Apresenta um âmbito cronológico e geográfico alargado: da Idade do Bronze ao Renascimento; da Grécia balcânica ao mar Negro, da Magna Grécia à Anatólia. Ártemis, que foi a deusa mais popular do panteão grego e uma das mais intrigantes também, como comprovam os santuários, iconografia e epigrafia, permanecia até agora ignorada pela historiografia. O carácter multi-facetado da divindade ecoa nos vinte artigos que constituem este volume (dividido em quatro partes), dezanove dos quais em inglês e um em alemão, uma mais-valia preciosa para a sua divulgação.

A primeira parte é dedicada ao Próximo Oriente e à Grécia. Marie Nosch (pp. 21-29) aborda a presença de Ártemis no Linear B e a sua possível origem na Potnia Theron ("Senhora dos Animais Selvagens") da Idade do Bronze e cuja iconografia mostra claramente os elementos que a tradição atribuiu à deusa grega, como a natureza ou os animais selvagens. Bodil Hjerrild (pp. 41-49), por sua turno, trata dos paralelos com o Próximo Oriente e das contradições que lhe encontramos. Se é a protectora dos animais, é também a caçadora que os persegue e mata com o seu arco e flechas. Deusa virgem, preside aos nascimentos, mas se ajuda as mulheres neste momento critico da sua vida é também a responsável pelas suas mortes inexplicáveis. Minna Jensen (pp. 51-60) concentra a sua atenção em Homero e na aparente contradição que encontra na pouca relevância que Ártemis assume nos Poemas Homéricos. Apesar de ser uma divindade poderosa, não foi tradicionalmente associada à Guerra de Tróia, ainda que tenha sido a ela que Agamémnon sacrificou Ifigénia para obter ventos propícios para navegar para Tróia. Jorgen Mejer (pp. 61-77), por sua vez, aborda o papel da deusa na literatura e religião atenienses, onde se torna claro que foi venerada em vários locais da cidade, em templos de pequena dimensão, mas que estavam associados a acontecimentos cívicos importantes. Esta faceta acaba por eclipsar, em certa medida, a Ártemis dos mitos, caçadora e deusa 
da natureza selvagem. O mesmo autor ( $\mathrm{pp}$. 79-81) apresenta ainda uma inscrição encontrada nas escavações dinamarquesas realizadas entre 2006 em Calydon, na Etólia. Inge Nielsen (pp. 83-116) concentra a sua atenção no santuário de Ártemis Braurónia e nos rituais aí realizados, através das fontes escritas, iconográficas e arquitectónicas. A autora tenta localizar os locais onde os rituais, mostrados em vasos cerâmicos encontrados no santuário, eram realizados. $\mathrm{O}$ artigo de Birte Lundgreen (pp. 117-126), estuda a cabeça de uma estátua de criança, supostamente encontrada no santuário da deusa em Braúron e adquirida em 1894 pelo Ny Carlsberg Glyptotek onde ainda hoje se mantém. O artigo centra-se nas diferentes interpretações feitas ao longo dos anos e na dificuldade que permanece na identificação e definição das funções dos objectos. A cabeça, que apresenta paralelos com algumas representações de Eros feitas por Praxíteles e Lisipo, pertence ao século IV a. C, e pode ter sido utilizada como oferenda votiva num santuário ou para assinalar uma campa num cemitério. Ditte Falb (pp. 127-152), apresenta, no único texto escrito em alemão, as estruturas que restam do tempo de Ártemis Orthia em Esparta, assim como as figurinhas de chumbo que são comparadas pela autora com exemplares semelhantes encontrados no Próximo Oriente, particularmente na Fenícia. Synnove des Bouvrie (pp. 153-190), no seguimento do texto anterior, apresenta o culto de Ártemis Ortheia em Esparta, o qual surpreende pelo enigma que sempre o rodeou e pela brutalidade que o revestia, e que é o aspecto mais conhecido. Os jovens espartanos eram flagelados, até sangrarem, ou, em alguns casos, até à morte, em nome da deusa, que curiosamente só assume o nome de Ártemis já no período romano, durante os Flávios, enquanto o culto de Ortheia se encontra atestado desde o período geométrico e se prolongou pela Antiguidade tardia.

A segunda parte da obra concentra-se, por sua vez, nos aspectos regionais do culto de Ártemis. Lone Sorensen (pp. 195-206) analisa os escassos vestígios encontrados em Chipre e assume, como não poderia deixar de ser, um carácter revisionista. As estátuas que apresentam Ártemis nos moldes típicos da iconografia grega e inscrições encontradas, apontam para a introdução do culto por volta do século $\mathrm{V}$ a. C., em simultâneo com outros cultos helénicos, e para a assimilação com a "Grande Mãe» venerada localmente. Tobias Hansen (pp. 207260) desloca-se para o Ocidente, mais propriamente para a Magna Grécia e Sicilia, onde uma vez mais Ártemis não parece ter sido uma deusa muito importante, ao contrário do que acontece com os cultos de Hera, Deméter e Perséfone, apesar de os primeiros vestígios do seu 
culto recuarem à fundação de Siracusa. O texto seguinte, da autoria de Marjatta Nielsen e Annette Rathje (pp. 261-301), desloca-se para o campo da etruscologia, onde abordam a extensão e limites do impacto grego a nível iconográfico e religioso na antropomorfização dos deuses etruscos, e em particular sobre a deusa Artumes, que vários autores ainda acreditam ser uma importação grega. Pia Bilde (pp. 303-332), apresenta uma visão global dos locais e períodos históricos onde Ártemis foi venerada na região do mar Negro, área para a qual não existia até aqui um estudo compreensivo. O texto destaca-se pela atenção que é dada às questões metodológicas, com a autora a apoiar-se nos diferentes tipos de fontes para evidenciar a existência do culto, apesar de nunca se ter descoberto um santuário que pudesse ser identificado com segurança dedicado à deusa na região. A presença da deusa na esfera pública é estudada através do nome do mês de Artemísion, templos e santuários, sacerdotes e sacerdotisas, dedicações e epítetos, presença da deusa nas emissões monetárias, enquanto a esfera privada se concentra nos nomes teofóricos. Luis Ballesteros-Pastor ( $\mathrm{pp}$. 333-340) concentra a sua investigação no mar Negro também para nos apresentar, através das evidências literárias, a possibilidade de ter existido em Themiscyra um santuário dedicado a Ártemis, divindade que era com frequência associada às Amazonas. O autor explora desta forma o papel simbólico, que a localidade pode ter assumido na antiguidade, visto ser um local de fronteira, entre a civilização e a natureza selvagem.

A terceira parte apresenta a Ártemis/Diana venerada durante o período republicano, o período imperial e na Antiguidade tardia. Mette Moltesen (pp. 345-367) apresenta um grupo de estátuas descobertas no templo de Nemi e compara-as com um fragmento, actualmente no Museu de Boston, e que se pensa pertencer também ao mesmo templo. Por sua vez, Jasper Carlsen (pp. 369-381) estuda a relação dos Domitti Ahenobardi, uma das famílias mais proeminentes da Roma tardo-republicana e imperial, com Ártemis através de duas inscrições, onde são referidos santuários da deusa e o seu contexto histórico. A atitude da família para com a deusa e os seus santuários no Mediterrâneo Oriental é ainda confrontada com a mostrada por outras famílias senatoriais para com os santuários de Diana em Itália, apesar de as evidências serem escassas. Rubina Raja (pp. 383-400) aborda o caso concreto de Gerasa, cidade jordana que apresenta um dos melhores conjuntos preservados de arquitectura clássica do Próximo Oriente romano, na tentativa de apurar a importância do culto de Ártemis na vida religiosa da cidade na época pré-antonina e a sua proeminência e escala durante os Antoninos. Raja 
argumenta que o santuário era não só o testemunho da importância da deusa na cidade como foi usado para aumentar o desenvolvimento urbano local. Birte Poulsen (pp. 401-425) tenta determinar o papel e o estatuto da deusa da caça e os seus locais de culto citados pelas fontes literárias, iconografia e inscrições votivas durante o período imperial e Antiguidade tardia. Niels Hannestad (pp. 427-451), debruça-se sobre um pequeno conjunto escultórico, descoberto em 1859 perto da aldeia de Bertrich, na Alemanha, que representa uma Diana caçadora acompanhada por um cão e que pode ter sido fabricada em Arles.

A quarta parte centra-se na recepção de Ártemis. Marjatta Nielsen (pp. 455-496) apresenta as metamorfoses de Ártemis Efésica, cuja iconografia tem sido alvo de numerosas interpretações, ainda que o motivo de ter o peito coberto com o que se pensou durante muito tempo serem seios, nunca ter sido questionado.

O Forum encerra o volume e concentra, além de uma análise de Alexandra Alexandridou (pp. 497522) ao material cerâmico da necrópole de Vari, datado dos séculos VII-VI a. C., e à sua função nas cerimónias fúnebres, um relatório onde se dá conta dos resultados das escavações dinamarquesas que decorrem na Grécia, na Turquia, em Ólbia (mar Negro) e na Itália, e ainda com duas recensões críticas.

Em conclusão, apresentamos uma edição que se destaca pelo cuidado com que foi preparada e organizada. Os textos, marcados por uma forte componente interdisciplinar num cruzamento feliz de dados literários, históricos e arqueológicos, são acompanhados por imagens a preto e branco e a cores de excelente qualidade, assim como por tabelas e mapas. As respectivas notas e bibliografia estão localizadas no fim do texto o que impede que o leitor perca o ritmo da leitura sempre que tenha de consultar uma referência bibliográfica. No final encontram-se os índices remissivos, organizados por fontes (pp. 573-577), nomes (pp. 578-581), e locais (pp. 582-585), e que permitem uma rentabilização da leitura ou da simples consulta por epíteto ou local. O seu âmbito geográfico e cronológico alargados tornam-na uma obra de consulta fundamental e permite em conjunto com os artigos publicados em revistas da especialidade uma melhor compreensão de Ártemis, que permanece ainda uma deusa esquiva e misteriosa.

Nídia Santos 